\title{
Szyszlo, signo americano
}

\author{
Szyszlo, american sign
}

Juan Gustavo Cobo (Colombia)

Escritor

coborda@gmail.com

\section{Resumen}

En este artículo, el escritor Juan Gustavo Cobo Borda rastrea posibles influencias en los temas que explora la obra de Fernando De Szyszlo. En el lienzo, el artista revela el lenguaje de una poesía ancestral que bebe de la influencia del surrealismo y los signos precolombinos y se escribe en una abstracta geometría mística.

Palabras clave: Szyszlo, pintura, arte latinoamericano, signos

\begin{abstract}
In this article, writer Juan Gustavo Cobo Borda traces possible influences on the issues that the work of Fernando De Szyszlo explores. On the canvas, the artist reveals an ancestral language of poetry that draws on the influence of Surrealism, pre-Columbian signs and is written in an abstract mystical geometry.
\end{abstract}

Keywords: Szyszlo, painting, Latin American Art, signs 


\section{Szyszlo, signo americano}

\section{Szyszlo, american sign}

Juan Gustavo Cobo (Colombia)

Escritor

coborda@gmail.com

"La pintura es una derrota. El desfase entre lo que sueñas hacer y lo que finalmente concibes". Con estas palabras, Fernando de Szyszlo, vuelve a Bogotá con medio centenar de sus grandes cuadros, y nos lleva a preguntarnos cuáles son entonces las dimensiones de su ambición. Porque las pinturas que cuelgan en los blancos muros del Museo de Arte Moderno son ejemplos elocuentes y muy válidos de un gran pintor, nacido en 1925 en Lima y hoy entregado, con furia y armonía, a seguir ahondando en un mundo propio.

El mundo donde el arte precolombino dialoga con la filosofía del surrealismo en un silente y hondo paisaje desértico y en el fondo de unos mares (Mar de Lurín), donde lilas, azules, morados, turquesas y magentas nos obligan a sentir la flora y la fauna de nuestro inconsciente. Del agua primordial.

Quien preside esta bien trenzada constelación de signos plásticos no es otro que un sol negro. "Inti", la piedra con que los incas lograban amarrar el sol. Por ello, este mundo de penumbras y veladuras busca también dejar afuera el paisaje e internarse en "cámaras rituales" donde se desarrollan singulares "ceremonias" plásticas. Mesas para sacrificios o lechos para el amor, donde insospechados visitantes de dos piernas y sin cabeza nos impactan con sus entrelazadas ramas.

Como lo escribió Octavio Paz, en 1959, la suya es "Una pintura que no se entrega, replegada sobre su propia intimidad, que desdeña la complicidad sensual y exige al espectador una contemplación más ascética. [...] Sus formas, tensas y veloces, a veces son agresivas, crueles; otras, sus colores 


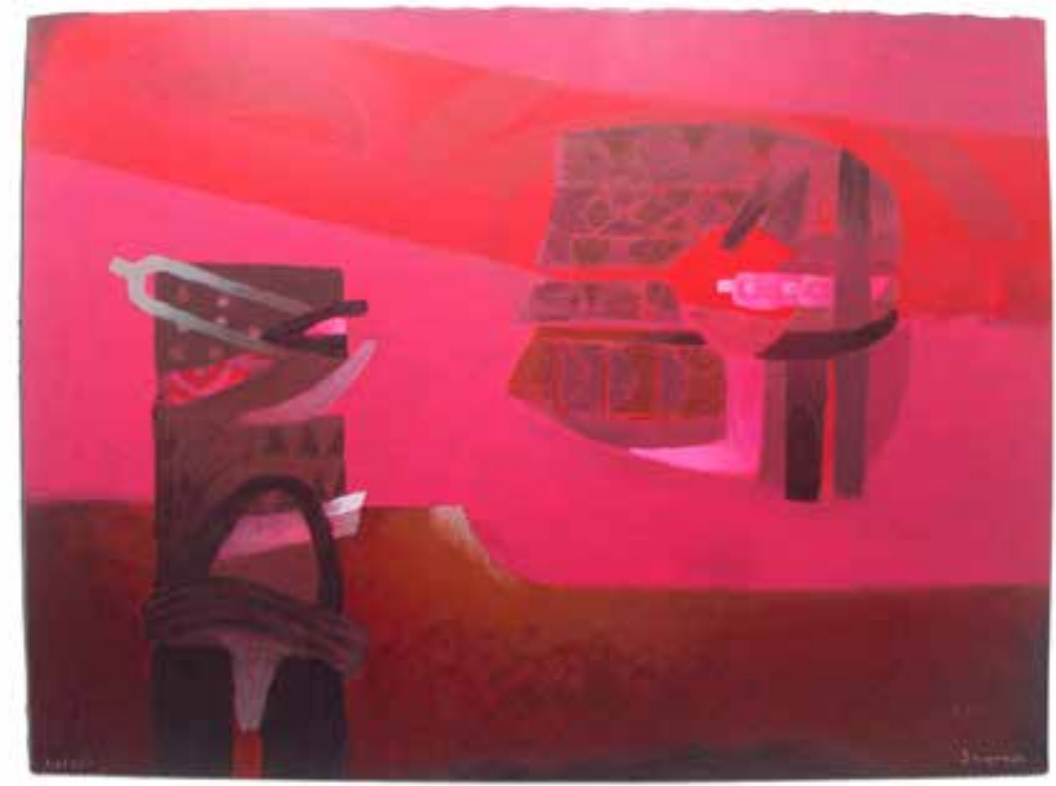

Serie Sol Negro, 1992

reconcentrados tienen destellos de salvaje entusiasmo". Todas estas características se han enriquecido con los años, en jugosos dípticos, sobre fondo rojo, donde las texturas no hacen más que incrementar los espacios, reforzándolos con su caligrafía. Los grandes y vigorosos trazos que comenzó a perfilar, desde la década de 1950, cuando pasó seis años en París $y$ fue reconocido por Hartung.

Época que lo nutre hasta hoy, cuando recuerda asombrado aún cómo estaban vivos Picasso y Calder, Camus y Sartre, Giacometti y Breton, y era factible encontrárselos en el café de Flore. Pero curiosamente ahí se volvió en verdad latinoamericano, dialogando y mirando las pinturas de Tamayo, Lam, Matta y Alejandro Obregón y reuniéndose con Octavio Paz, Julio Cortázar, el poeta peruano Eielson, y los españoles Palau y Fabre y Arturo Serrano Plaja, para soñar, cómo no, con una revista cultural, con título prestado de Larra: "El pobrecito hablador".

Eso no se olvida, como sus comienzos en Perú, donde se inscribió en Arquitectura y visitaba con el poeta Javier Sologuren el Museo de Arqueología en Lima deslumbrándose con los vibrantes tejidos pintados de Chancay y el arte de la cultura Chavin. También la figura de José María Arguedas, novelista y a la 
vez antropólogo, lo llevaría a buscar para sus telas esos mitos aglutinantes, como podían ser la tortura y la muerte del inca Atahualpa, recreados en una elegía quechua, o ahondar, año tras año, en la poesía de César Vallejo y César Moro, recibiendo por esa fidelidad imprevistas recompensas. La viuda de Vallejo, en París, le regalaría un mechón póstumo de su pelo de cholo, que aún conserva en el mismo sobre en que se lo entregó.

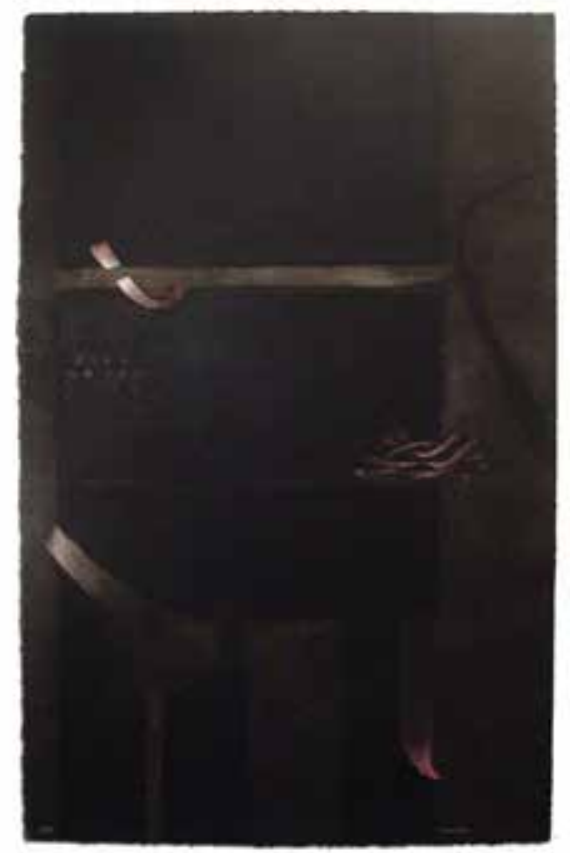

Camino a Mendieta, 2006

Búsqueda de un lenguaje contemporáneo (cubismo, abstracción, surrealismo, tachismo), poesía ancestral del mundo precolombino y muy personales vivencias cristalizadas van configurando el mundo de Szyszlo. Un mundo que se tiende hacia el horizonte y un mundo que se hunde en sus raíces.

En ocasiones jambas y dinteles y escaleras que traen consigo la luz nos concretan en su nitidez geométrica, solo para obligarnos a descender a esa casa de su mente donde el enigma torna e interrogarnos con sus formas convulsas. Con ese nudo tenso y agitado, envolviéndose en sí mismo, y en tantos casos circundado por esas gotas semillas que marcan contrastes y hacen aún más visibles las corrientes de tensión. Esas franjas de energía que arrastran la mirada en lenta y ondulante marea cromática, de paralelismo y acordes, de repliegues y expansión.

Lo emotivo de su color y lo sabio de su composición despliegan en esta muestra de Bogotá la dilatada y fecunda trayectoria de este maestro que, desde el mundo andino, se hizo partícipe de un diálogo universal, con su inconfundible geografía anímica de abigarrados encuentros de luz y sombra. De oscuros discos que refractan colores muy vivos, de diálogos eróticos entre la grieta y el asta, como señaló muy bien el poeta Sologuren, donde la convexidad que acoge y el filo que a la vez hiende y 
produce placer surgen de un color que aún arde en su negra tumba. O que se transforma en un haz de signos, amarrados por su mano tan dúctil como sabia. Esas formas rotundas, situadas en mitad de esos espacios magnéticos, nos transmiten la fosforescencia de sus pigmentos, como si desde la oscura boca de la sombra el dorado resplandor de una claridad efímera brotara nuevamente. Es la luz con que la pintura ilumina una vez más el camino del hombre, brindándole el don inextinguible de la perpetua ambigüedad. De volver a mirar esta pintura inagotable, que late dentro de la tela y en lo más profundo de nuestra visión.

Fernando de Szyszlo

Los lenguajes del arte

Museo de Arte Moderno de Bogotá 8 de septiembre a 8 de octubre 8 de 2009

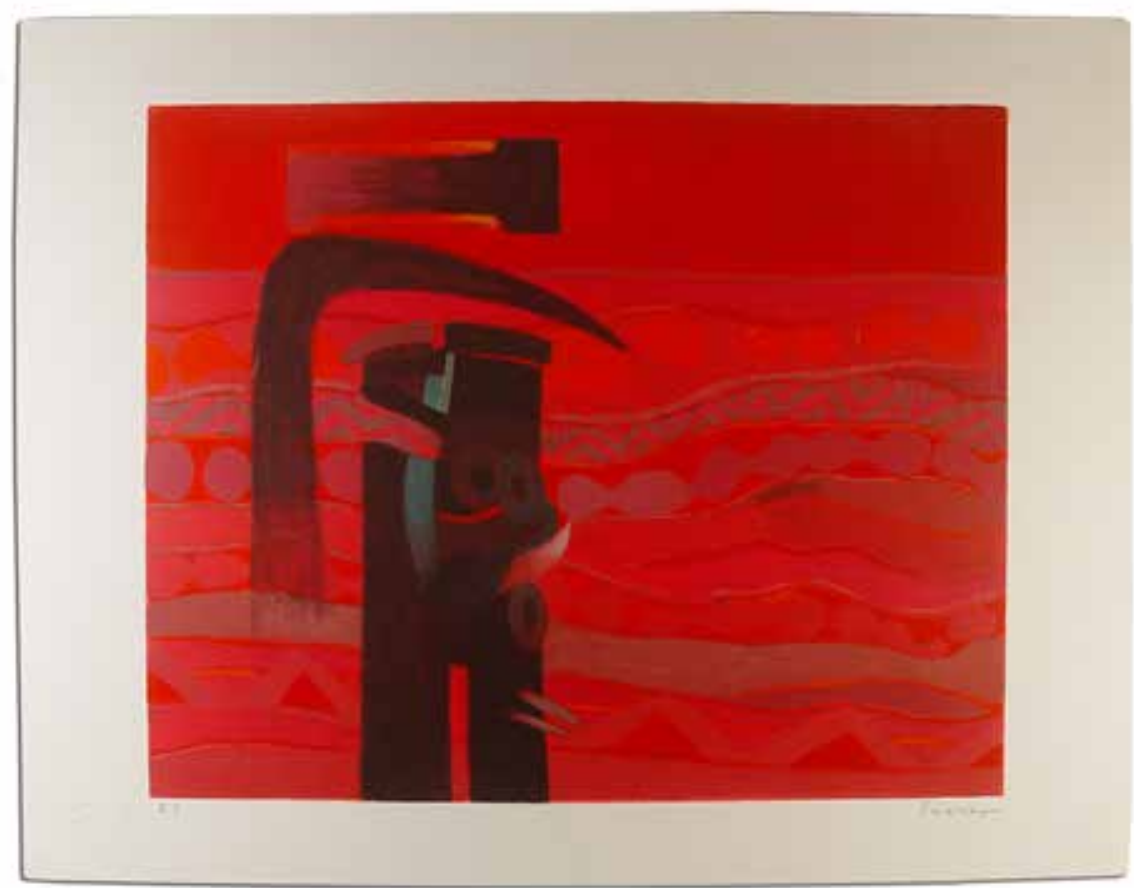

Camino a Mendieta, 2006 
- Szyszlo, signo americano - Juan Gustavo Cobo

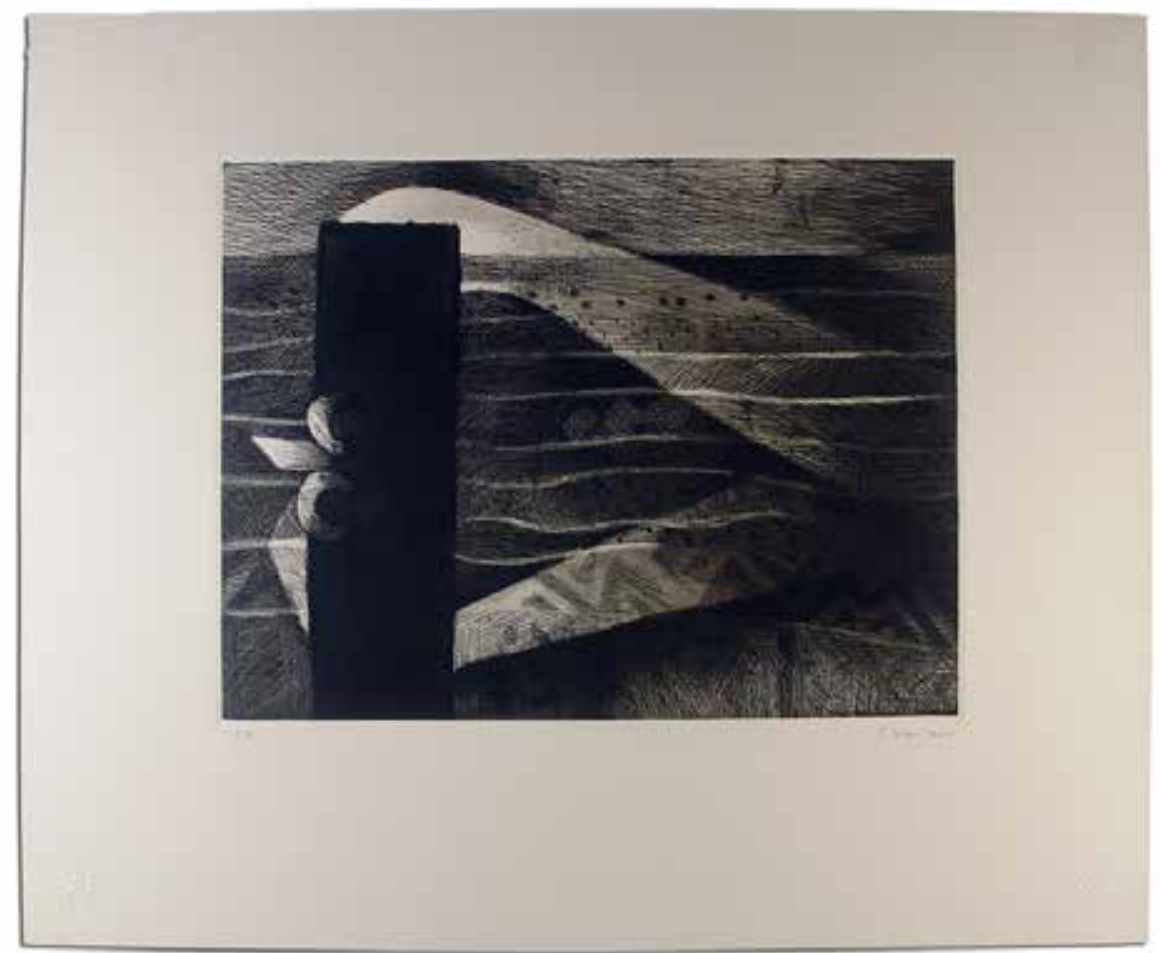

Sin título, 1991 